УДК 1(091)

DOI https://doi.org/10.24866/1997-2857/2021-4/99-107

\title{
И.А. Приходько* \\ СРАВНИТЕЛЬНЫЙ АНАЛИЗ ФЕНОМЕНА САМОУБИЙСТВА В ФИЛОСОФСКОМ И ЛИТЕРАТУРНОМ ДИСКУРСАХ ХХ В.
}

\begin{abstract}
В статье рассматривается феномен самоубийства на границе философии и литературоведения на примере нескольких работ, написанных в XX в. Автор отмечает, что проблема самоубийства в обеих сферах познания в большинстве случаев не является основной темой произведений и затрагивается мыслителями и писателями вскользь. В одну логическую цепочку связываются воззрения на феномен самоубийства М. Бланшо, Г. Чхартишвили и Р. Барта, каждый из которых, рассматривая суицид сквозь призму категорий возможности, творчества, любви и др., выделяет специфические мотивы добровольного ухода из жизни.
\end{abstract}

Ключевые слова: самоубийство, смерть, мотив, философский дискурс, литературный дискурс

Comparative analysis of the phenomenon of suicide in the philosophical and literary discourses of the $\mathbf{X X}^{\text {th }}$ century. IRINA A. PRIKHODKO (Far Eastern Federal University)

The article examines how the issue of suicide was treated in the philosophical and literary discourse in the $\mathrm{XX}^{\text {th }}$ century. The author notes that in both fields this issue in most cases did not constitute the main topic of the works by writers and thinkers and was touched upon in passing. It is concluded that the $19^{\text {th }}$-century writers had a deeper understanding of suicide than the $\mathrm{XX}^{\text {th }}$-century philosophers who were influenced by them and tended to switch to literary discourse when addressing the issue of suicide. The author focuses on the works of M. Blanchot, G. Chkhartishvili, and R. Barthes who studied suicide through the prism of such categories as opportunity, creativity, and love, using a sublime literary language.

Keywords: suicide, death, motive, philosophical discourse, literary discourse

Самоубийство - в какой бы то ни было культуре, каким бы ни было отношение к нему общества, религиозных групп, политических лидеров и т.д. - всегда будоражило сознание человека. Мнения по поводу природы самоубийства до настоящего времени разнятся. Одни считают, что тот, кто добровольно решается покинуть этот мир, страдает малодушием и, ставя точку в своей жизни и не желая бороть- ся за нее, проявляет крайнюю слабость. Другие видят в подобном исходе жизненного действа великую трагедию, сопровождающуюся не менее великим пафосом и красотой своеволия, перемещая тем самым феномен самоубийства в область эстетики. Третьи не относятся к лишению себя жизни всерьез, видя в суициде лишь заигрывание со смертью или экстравагантную попытку привлечь внимание. Наконец, есть и

* ПРИХОДЬКО Ирина Анатольевна, аспирант Департамента философии и религиоведения Школы искусств и гуманитарных наук Дальневосточного федерального университета.

E-mail: prikhodko.ian@dvfu.ru

(C) Приходько И.А., 2021 
те, кто считает, что с помощью самоубийства человек желает заглянуть за черту бытия, узнать, что таится за его пределами. Разумеется, здесь приведены далеко не все трактовки феномена самоубийства. В рамках европейской философии суицид долгое время рассматривался в аспекте решения вопроса о его правомочности и возможности его совершения с позиций общежития, а затем, когда христианской религией были даны неоспоримые негативные ответы на обозначенные выше вопросы, более глубокое погружение в изучение этого неоднозначного явления было отложено на века. И несмотря на то, что апология самоубийства все же состоялась в Новое время, философы не сразу углубились в метафизические изыскания в данной сфере. Иную картину мы можем наблюдать в литературе, которая столетиями дарила читателям проникновенные истории героев-самоубийц, диалектически прослеживая зарождение, развитие и исполнение их суицидальных намерений. Однако литература и философия все больше сближаются по ряду объективных причин: «во-первых, для адекватного постижения процессов, происходящих в современной культуре, необходимо определенное метафизическо-литературное отражение и переосмысление ... феноменов, во-вторых, для философии и литературы существуют общие механизмы самовыражения, среди которых особенно стоит отметить метафору и стиль, в-третьих, философия и литература содержательно пересекаются, когда ставят и разрешают метафизические проблемы» [1, с. 62]. Наиболее явно данное сближение стало проявляться в XX в., поэтому на предмет данной статьи - феномен самоубийства - мы смотрим именно через призму философского и (около)литературного дискурса этого периода, ограничиваясь несколькими яркими примерами, балансирующими на грани философии и литературоведения.

Французский мыслитель Морис Бланшо затронул тему самоубийства, рассуждая о природе литературного творчества, продукт которого тесно связан с бытием в целом. Параллельно с данной точкой зрения, М. Бланшо развивает мысль о том, что произведения искусства, созданного писателем, внутри бытия не существует, «оно никогда не существует наподобие вещи или какого-либо сущего вообще» [4, с. 36]. В пространстве литературы имеется утверждающий себя в большей степени здесь, чем в какой-либо иной сфере, язык, но в той мере, в какой язык для литературы является всем, точно так же он волен обратиться в ничто, ведь «слова обладают способностью заставлять вещи исчезать» [4, с. 36]. Слова, «повелители отсутствия» [4, с. 36], таким образом выполняют действия разрушительного характера или, если быть более точными, саморазрушительного, похожего на самоубийство - явление, которое М. Бланшо считает странным. Рассуждая о поэзии С. Малларме, М. Бланшо приходит к выводу, что творчество данного поэта имеет прямую корреляцию с его отношением к смерти, «поэма... является возможной, только если возможна смерть, если через самопожертвование и напряжение, коим подвергает себя поэт, она становится в нем способностью, возможностью, если она является действом, действием по преимуществу. Смерть - это единственно возможное действие» [4, с. 37]. Посредством добровольной смерти человек одновременно уничтожает и утверждает себя; для творческого человека особенно остро стоит вопрос о том, может ли он умереть, обладает ли он такой способностью, потому, создавая произведения (сам процесс их создания приближает смерть), он стремится к той точке, в которой его «творение противостоит невозможности» [4, с. 37].

М. Бланшо признает, что вверение писателю в качестве мотивации к творческой деятельности стремления к обладанию способностью к умиранию бросает вызов здравомыслию, ведь смерть непременно наступает в жизни каждого человека, при этом без особой его заботы и хлопот. Тем не менее, помыслить смерть едва ли возможно, ведь ни у кого нет достоверных данных о ней, что влечет за собой частое избегание темы смерти в мыслях отдельно взятого индивида. Человек мысленно бежит от смерти, но нет более глубокого укрытия от смерти, чем она сама, «прятаться от смерти - некоторым образом то же самое, что прятаться в ней» $[4$, c. 93]. Подобное видение смерти рождает отношение к ней как к задаче, стремление к ее выполнению наполняет жизнь человека смыслом и приближает его к постижению истины. М. Бланшо не обходит вниманием персонажа романа Ф.М. Достоевского «Бесы» Алексея Ниловича Кириллова, ставшего, по мнению Г. Чхартишвили, самоубийцей № 1 во всем мире в плане его популярности среди исследователей феномена суицида. Самоубийство Кириллова, которое французский мыслитель на первый взгляд как будто возводит в ранг ге- 
роического, так как оно является воплощением высшей формы смерти, противопоставляется не достойной уважения естественной смерти, всегда застающей человека, не осмелившегося покинуть жизнь добровольно, не в то время и не в том месте. Смелость и истинная любовь к жизни приносят свои плоды: превращая смерть в возможность, они как будто приручают смерть, делают ее послушной, не позволяют человека застать врасплох. Не лишенная неточностей и сбивчивости теория Кириллова вызывает на дуэль сам Абсолют: столь сильное, всеобъемлющее владение собой не только в жизни, но и в смерти, ставит под сомнение существование Бога, распоряжающегося судьбами человеческими. Убивая себя, Кириллов желал открыть глаза человечеству, продемонстрировать образец своеволия, открыть новую эру, в которой люди научатся владеть собой и отпадет необходимость в последующих самоубийствах. Собственноручное сотворение дара смерти стало бы для Кириллова еще более ценным, если бы он точно знал, что существует бессмертие (не потустороннее), ведь в таком случае самоубийство явилось бы единственной возможностью проявить свою человечность в мире, обрекающем нас на вечную жизнь.

Все вышесказанное, однако, не утверждает однозначную героизацию феномена самоубийства французским писателем и эссеистом он также выделяет изъяны вольной смерти. М. Бланшо полагает, что человек, способный совершить самоубийство, должен обладать достаточной силой, следовательно, его жизнь могла бы еще продолжаться. «...Кто убивает себя, тот сохраняет надежду, надежду со всем покончить; в надежде проявляется его желание начать сначала, в самом конце вновь обрести начало, утвердить тем самым некое значение, которое он сам же и оспаривает, умирая. Отчаявшийся не может уповать ни на добровольную, ни на естественную смерть: у него нет времени - нет настоящего, нынешнего времени, чтобы опереться на него для смерти. Убивающий себя великий утвердитель нынешности» [4, с. 101]. Способность самоубийства к утверждению обосновывается тем, что, только добровольно покидая жизнь, человек сам выбирает время своей смерти; если бы можно было заранее оговорить момент своей смерти, вероятно, суицид потерял бы свое столь важное значение.

В отношении М. Бланшо к смерти наблюдаются следы своеобразного эпикурейского ее отрицания (мы знаем, что смерть неизбеж- на, но в момент, когда она наступает, уже нет осознающего ее человека), что сказывается и на размышлениях, касающихся предмета данной статьи. Так, М. Бланшо полагает, что самоубийца всегда ставит перед собой цель, в которую невозможно попасть, «смерть не помещается во времени труда», «есть как бы двоякая смерть: одна заключена в кругу таких слов, как “возможность” или “свобода", предел ее составляют свобода умереть и возможность рискнуть собою в смерти; другая же представляет собой нечто неуловимое, я не могу ее схватить, она не связана со мною никаким отношением, она никогда не наступает, и сам я к ней не направляюсь» [4, с. 102]. Такой подход к исследуемому вопросу в некоторой мере сгущает чары недоступности познания, которые окутывают данный феномен, показывает его «странно-поверхностную» и «чарующе-обманчивую» природу. Убивающий себя шагает навстречу смерти, над которой он ощущает власть, но рассчитывает получить в итоге ту смерть, управлять которой он уже не сможет и которая также не имеет власти над ним, образовывая при этом между самоубийцей и смертью отношение «пустой интимности неведения» [4, с. 102]. Самоубийство обретает характер азартного пари, ведь совершающий его, заранее приняв осмысленное решение покончить с собой, совершает прыжок во мрак неизвестности, туда, где нет места ни решениям, ни воле, ни какой-либо достоверности. Каким бы образом ни пришла смерть - по естественным причинам, в результате несчастного случая или самостоятельно вынесенного себе приговора покинуть мир - сущности смерти это не меняет. Стремление лишить будущее неизвестности и избрание для достижения данной цели самого радикального пути бессильны перед «темно-заповедным обиталищем непроницаемой смерти» [4, с. 103].

Для совершения самоубийства, ровно как и для создания творения, необходимо обладать долей безумства, ведь и самоубийца, и творец устремлены к тому, над чем они не имеют власти, что нельзя помыслить. Оба, подобно самураю, имеют путь, но не имеют четкой цели, потому что она неуловима, результат их действий трудно запечатлеть, и, более того, сами они не ведают, что творят. Объекты их желаний попросту игнорируют их волю в настоящем времени, но каким-то образом (изначально неизвестно каким) результат их осуществления воплотится в бесконечности. 
В «Пространстве литературы» М. Бланшо также можно выделить еще одну черту, сближающую творческого человека с самоубийцей, одиночество. Подхватывает данную мысль Григорий Чхартишвили, утверждая, что творческая деятельность в большинстве случаев осуществляется человеком в одиночестве, творец противопоставляет себя другим людям, и нити, связывающие его со всем, что удерживает в жизни, развязываются, что выливается в стандартную суицидальную установку. При этом Г. Чхартишвили подчеркивает, что в своей работе «Писатель и самоубийство» он уделяет внимание вольной смерти представителей именно данной сферы деятельности по той причине, что писатели более выразительно и более ясно вербализируют мысли суицидального характера во всей их диалектике. Литераторы часто сталкиваются с соблазнительной идеей самоубийства, разумеется, примеряя данную идею к своей персоне. Искусство самоуничтожения завораживает сознание писателя, и, будучи предельно открытым, постоянно изливая свою душу на страницах произведений, он остается обнаженным перед лицом охватывающего его ужаса. Чернила, которыми автор выдает себя на страницах произведений, являются аналогом крови писателя или же аналогом чернил, которые выпускает из себя осьминог. И для пишущего человека, и для осьминога чернила - это внутренняя секреция, выделение которой способно привести к гибели.

Однако в целом самоубийство писателя не отличается от самоубийства человека, «не инфицированного бациллой творчества» [8, c. 323], мотивы совершения суицида не сильно разнятся у представителей разных профессий, за исключением экстраординарных случаев, которые также можно встретить среди людей, далеких от творческой деятельности, хотя, как уже отмечалось, риск покончить с собой выше именно у литератора. Творчеством, по мнению Г. Чхартишвили, занимаются лишь те, у кого изначально отмечается слабо выраженный инстинкт самосохранения. Писателя автор уподобляет ребенку в силу его особой эмоциональной открытости, свежести взгляда, для него Критик выступает в качестве архетипа взрослого, отца, недовольного поступком ребенка. Повышенный уровень ранимости делает человека беззащитным, и в депрессивные моменты на сцену жизненного действа писателя выходит синдром самозванца. Творцам иного толка в этом пла- не приходится легче: художник обязан владеть кистью, красками, определенными техниками, оттачиваемыми из года в год, композитор оканчивает консерваторию, умеет играть на музыкальных инструментах, изучает теорию музыки и т.д., - иными словами в профессионализме представителей других творческих профессий мало кто сомневается, в то время как писатель обладает только буквами, его набор инструментов скуден и владеет им каждый даже малообразованный человек.

Высокий уровень суицидального риска отмечается также среди врачей, которых Г. Чхартишвили сравнивает с писателями (первые врачуют тело, вторые осуществляют попытки излечивать душу), а также среди военных и бизнесменов. Но именно писатель стоит ближе к роковой черте, которую тянет переступить, когда он становится заложником языка и смешивает жизнь со страницами романа. К другим специфическим причинам, побуждающим к совершению «литературицида» (термин, заимствованный у Артюра Рембо), автор относит: страх потерять дар, лишиться вдохновения; эмиграцию (это «суицидоопасное испытание» $[8$, c. 439], корни которого лежат в дюркгеймовской дезадаптации и аномии в обществе, имело такие печальные последствия еще для античных писателей); желание самостоятельно придумать и исполнить финал своей романической жизни.

Анализ других приведенных Г. Чхартишвили мотивов к совершению самоубийства носит скорее характер литературный и отчасти социологический, и тем не менее обратимся к ним. Комплекс мотивов, указанных в разделе «Как у людей», включает в себя:

- нужду - «скучный» мотив с налетом достоевщины. Ярчайшим примером самоубийцы из-за бедности автор «Писателя и самоубийства» считает навсегда оставшегося юным поэта Томаса Чаттертона (1752-1770), который на свои последние гроши предпочел приобрести не хлеб, а яд, избрав аристократическую смерть от собственной руки в противовес вульгарной смерти от голода;

- юность - возраст, опасный своими спонтанными порывами, пробуждением творческих сил разного масштаба, а также не успевшей сформироваться «привычкой жить» [8, с. 325], отсутствием веры в действительность своей смертности и максимализмом, который в период так называемой черной полосы в жизни или 
всего из-за одной неудачи может толкнуть к добровольной смерти. В ряды безвременно погибших юных дарований мог вступить А.А. Блок, который, отправляясь на студенческий бал, где он потребовал ответа у своей возлюбленной Л.Д. Менделеевой, заранее подготовил и оставил в кармане записку о том, чтобы в его смерти никого не винили. К счастью, эта записка поэту не пригодилась;

- cmaрость - при анализе данного мотива к совершению суицида Г. Чхартишвили выявляет парадокс: сегодня, когда людей преклонного возраста стало гораздо больше, чем в более ранние эпохи, подавляющее большинство населения мира желает дожить до глубокой старости, однако старости люди боятся и сталкиваться с ней не хотят. Человек хочет цепляться за жизнь в любом возрасте, ему непременно нужно дойди до такого состояния, которое в молодости и зрелости порой вызывало у него чувство отвращения. Японский писатель Сюсаку Эндо в работе «О чем я думаю, умирая» отмечает, что в биографиях известных писателей много внимания уделяется молодым годам, но почти никогда не описывается их жизнь в возрасте, когда они приближаются к естественному уходу к мир иной, что он считает несправедливым. Статусу старика в обществе никто не завидует, несмотря на наличие у того богатого опыта, которым он хочет делиться с молодыми, но на него не обращают внимания. В этом заключается одновременно и трагичность, и комичность ситуации, осознание и болезненное восприятие которой при шаткой психике способно довести до фатального исхода жизни. «Если человек в глубокой старости решает поставить точку самостоятельно - что это значит? Только одно: он защищает свое достоинство, свое “я”» [8, c. 336]. По мнению Г. Чхартишвили, традиция гордого суицида в старости пустила корни еще в античной философии. Так, Зенон Китионский, проживший долгую жизнь, в преклонном возрасте ожидал знака, который подвиг бы его к вольной смерти. Однажды, споткнувшись, философ коснулся земли пальцем, в чем он и увидел тот самый знак зовущей его в свою обитель земли и покончил с собой;

- болезнь - это обстоятельство способно выбить из колеи даже самых ярых противников самоубийства, терзая их муками и не оставляя шансов выжить. Подобно гордому старику, образ которого был описан в предыдущем пункте, человек, пораженный опасной болезнью, стра- шится испытать унижение, вызванное потерей своей неповторимой личности и нежеланием быть обузой для близких. Неизлечимая болезнь провожает человека за черту жизни, изменяя его состояние в несколько этапов: отрицание идеи смерти, гнев, торг, подавленность и, наконец, принятие своей участи [8, с. 381]. Самоубийство чаще всего люди совершают на этапе подавленного состояния, когда становится невыносимой не только физическая, но и душевная боль. Например, немецкая писательница Сандра Паретти не смогла примириться со своим диагнозом (онкология) и перед лишением себя жизни отправила в газету стихотворение, в котором характеризует свой поступок как «красивый и легкий финал, слегка подсвеченный нетерпением» [8, с. 387], о котором другим не стоит сожалеть. Тем не менее для совершения mors voluntaria писателю достаточно и совместимой с жизнью болезни, которая, однако, делает невозможной творческую деятельность;

- пьянство, наркотическая и медикаментозная зависимость - причины, являющиеся «главным поставщиком самоубийц» [8, с. 387]. Писатели чаще всего становятся заложниками указанных пагубных привычек ради самого состояния опьянения, которое кажется им их нормальным состоянием. Данный вид эскапизма для литераторов все же скорее является сопутствующим фактором, который только усиливает переживания иного характера, особенно если они возникают в периоды, когда вдохновение уходит в затишье. Или же, наоборот, слишком громкие успехи также покушаются на жизнь тихих, скромных писателей. Японский литератор Кавабата Ясунари, получив одну из самых престижных наград - Нобелевскую премию, стал страдать бессонницей и тревожностью. «Высокая награда, а в еще большей степени жадное внимание прессы парализовали творческую энергию интровертного певца тихой грусти и неброской красоты» [8, с. 397]. Он стал зависимым от снотворного, которое он принимал в большом количестве, а когда оно перестало оказывать необходимый эффект, желание уснуть у писателя стало настолько сильным, что страх уснуть навсегда отступил, и Кавабата Ясунари отравил себя газом;

- политику - сферу жизни, которая нуждается в мощном и действенном инструменте влияния на массы, коим в разные исторические периоды служило слово. Такая власть литературы (художественной, философской, научной и т.д.) 
выступает на политическую арену тогда, когда политическая ситуация становится нездоровой. Последствия пристального внимания и читателей, и политиков (при этом вторые стремятся подчинить себе писателя, устанавливая диктатуру над его творческими порывами) с учетом тонкой душевной организации литераторов не заставляют долго ждать: часть писателей продолжает играть по правилам, которые устанавливаются «наверху», другая - противится угнетателям, подвергая себя опасности. Первых политическая ангажированность нередко приводит к жизненному и творческому бессилию, в то время как противники политических плясок под чужую дудку посмертно становятся объектами народной гордости, как, например, поэт Галактион Табидзе, выбросившийся из окна психиатрической клиники, чтобы не подписывать письмо, призванное опозорить знаменитого коллегу - Б.Л. Пастернака;

- безумие - в противовес психической нормальности расположено в том же поле, что и творчество. Г. Чхартишвили считает, что те, кто в качестве своей профессии выбрал извлечение своих мыслей, переживаний, потаенных уголков сознания и изложение их на бумаге, далеки от «нормальной» части населения. «Творческий человек слишком безоглядно снимает урожай со своей души» [8, с. 413]. Безумие писателя порой толкает его на эксцентричные поступки, к числу которых можно отнести и самоубийство. Жизнь писателя Жерара де Нерваля протекала в очевидном разрыве с реальностью: он был влюблен в малоизвестную актрису Дженни Колон, которую называл Вечной Женщиной и центром мироздания. Когда актриса умерла, писатель стал отождествлять ее с Богоматерью, а себя впоследствии возомнил Богом, способным одним только взглядом причинить ущерб блюстителям порядка, сопровождавшим его в участок за очередную выходку. Перед смертью, ночью, не имея денег, де Нерваль пришел к своему приятелю с тем, чтобы сообщить ему о своем долге скупить все монеты, на которых изображен император Нерва, чтобы руки недостойных не касались лица его великого мнимого предка. Затем писатель попытался вернуться в место, где он ночевал, но там ему не открыли дверь. Побродив по улицам зимнего Парижа, де Нерваль удавился на глазах у прохожих;

- странности характера - мотив для совершения самоубийства, похожий на предыдущий экстравагантностью творческой личности, но отличающийся отсутствием у нее психопатологического диагноза. Интересной до последнего дня жизни была биография итальянского философа и математика Джироламо Кардано. Для своего нетолерантного времени он выбрал слишком неординарный, даже опасный профессиональный и творческий путь: помимо математики, врачевания и философствования, занятий непредосудительных, он также увлекался астрологией, которую считал своим главным предназначением. Его репутация пошатнулась после того, как он предсказал юному королю Эдуарду II долгие годы жизни, вскоре после этого король скончался. Дж. Кардано мучила такая большая ошибка, и он решил спасти свою репутацию новым пророчеством. На этот раз он предсказал, что его самого смерть настигнет в его 75-й день рождения, незадолго до которого он перестал принимать пищу и, таким образом, подтвердил точность своих слов;

- «последнюю каплю» - обычно суицидент перед осуществлением расправы над самим собой пребывает в подавленном состоянии, при котором он видит множество причин для преждевременного ухода из жизни. Однако силы, удерживающие его от рокового шага, пропадают после наступления кажущегося со стороны несущественным обстоятельства, которое становится последней каплей в чаше терпения. У каждого человека объем такого метафорического сосуда разный; у писателя, обладающего болезненным мировосприятием, которое и помогает ему творить, запас терпения не так велик. Одним из примеров самоубийства, совершенного под натиском данного мотива, является уход из жизни М.И. Цветаевой. Доподлинно неизвестно, что именно стало для поэтессы той самой «последней каплей» среди комплекса возможных причин: тяжелая жизнь в эвакуации, пессимизм и кажущаяся беспросветной тьма жизни, трудные отношения с сыном и т.д. Также стоит учесть, что финальная точка в жизни М.И. Цветаевой была не первой попыткой покончить с собой;

- ympamy, под которой чаще всего подразумевается потеря близкого человека или прекращение отношений с ним (но данный аспект ближе к мотиву любви, о котором будет сказано далее), а также потеря каких-либо качеств или ценного материального объекта. В данном случае образцом самоубийства служит римский комедиограф Публий Теренций, который при переправе из одного города в другой попал в 
бурю, затянувшую сундук с его комедиями на дно моря. Комедиограф был настолько опечален потерей своих творений, что бросился из лодки вслед за бесценным грузом;

- любовь (в том числе однополую) - «сильнейшее из доступных человеку переживаний» [8, с. 356]. К самоубийству человека способен подтолкнуть как трагизм неразделенной любви, так и состояние окрыленной счастливой любовью эйфории. «Чересчур разделенной» любви абстрактной фразы «пока смерть не разлучит нас» становится недостаточно, влюбленные желают быть вместе не только при жизни, но и после нее. Каноническим примером самоубийств, совершаемых по данной причине, является японский ритуал синдзю, при котором оба партнера кончают с собой в один день (хотя на самом деле зачастую в данном ритуале присутствует одно убийство - женщины - и самоубийство мужчины). В европейской культуре таким образцом могут служить двойные самоубийства супругов в Древнем Риме. Так, в «Письмах» Плиния Младшего встречается отрывок, в котором рассказывается история смерти консула Цецины Пета и его жены Аррии. Консул был приговорен к собственноручной расправе над собой, но страх смерти заставлял его медлить. Тогда Аррия, выхватив кинжал из рук мужа, нанесла себе глубокую рану, сказав при этом мужу «Пет, не больно», что подвигло его на незамедлительное исполнение приговоpa $[8$, с. 362].

Неразделенная любовь для писателя более эффективна, она в большей степени питает его воображение: «Страдания неутоленной страсти подарили человечеству куда больше шедевров, чем сытое мурлыканье любви благополучной. Однако безответная любовь для литератора не только возбуждающее средство, но и безжалостный убийца, на кровавом счету которого не один десяток писательских смертей» [8, с. 358].

В новейшей истории человечества данный мотив утратил долю популярности среди самоубийц, человек стал менее сентиментален, хотя и в XX в. можно найти множество примеров писательских суицидов (как и среди представителей других сфер деятельности), вызванных несчастной любовью. Однако в XVIII-XIX вв. количество подобных случаев было в разы больше, что, вероятно, отчасти было вызвано романтизацией образа Вертера - героя произведения И.В. Гете. Своеобразную трактовку суицидальных намерений и действий Вертера дает французский мыслитель Ролан Барт, не раз обратившийся к теме самоубийства в работе «Фрагменты речи влюбленного» (1977). Для Барта самоубийство - это один из вариантов исхода истории любви, но «есть влюбленные, которые не кончают самоубийством: из этого “туннеля”, следующего за любовной встречей, я могу и выбраться, вновь увидеть белый свет - либо я сумею найти диалектический выход из несчастной любви (сохранив любовь, но избавившись от ее гипноза), либо, отказавшись от этой конкретной любви, я устремлюсь дальше, пытаясь повторить с другими встречу, которой я по-прежнему ослеплен...» [3, с. 118]. Барт уделяет больше внимания дискурсу любви трагической, неразделенной, поэтому в его работу органично вплетается анализ суицидальных намерений, которые нередко сопровождают мучительные переживания человека, потерпевшего неудачу на сердечном фронте. Из кризиса в счастливой в целом истории любви или из несчастной любви влюбленный субъект желает выйти: представляя вариации выхода из сложившегося тяжелого положения, с которым влюбленный субъект не может и не хочет мириться, он находит таким образом мимолетный покой. Но, так как, по Барту, природа любовного чувства имеет характер языковой и сводится лишь к идеям, влюбленный субъект осознает, что «идея выхода соответствует полной безысходности: любовная речь - это некоторым образом разговоры о Выходах взаперти» [3, с. 121], а сам выход представляет собой лишь фантазм, соответствующий роли кого-то другого, выбравшегося из смертельно опасной любовной паутины.

Влюбленный субъект постоянно находится внутри клубка противоречивых интерпретаций действий Объекта его любви, что проявляется в стремлении распознать шифры и тайные знаки, якобы посылаемые Объектом. Практика семиологии влюбленного субъекта осуществляется внутри «системы недостоверных знаков» [3, с. 159], круга, полюсами которого служат такие позиции как «другой должен мне то, в чем я нуждаюсь» и «не-желание-владеть» (ничем от другого) [3, с. 149]. Вторая позиция автором приравнивается к «вывернутому наизнанку заместителю самоубийства» [3, с. 149]: Вертер покончил жизнь самоубийством как раз тогда, когда он смог отказаться от Шарлотты.

Воображение превращает влюбленного в жертву, так как он сам разыгрывает в своем 
сознании драматическую театральную постановку, ускоряя процесс принятия решения о самоубийстве мыслями о невозможности более пребывать в таких угнетающих обстоятельствах. Сам И.В. Гете тонко отмечал состояние смятения Вертера, его «лихорадочное, болезненное возбуждение, гнавшее его от одной крайности к другой» [5, с. 158], что имело своим результатом чувство отвращения к жизни. Ощущая себя абсолютно лишним (и в жизни, и в смерти), отвергнутым, изгнанным, без взаимности влюбленный в другого способен влюбиться в смерть, которая освобождена от умирания: «...И вот мой фантазм: сладостное кровотечение, которое не проистекает ни из какой точки моего тела, почти немедленно снедающее меня, с таким расчетом, чтобы я, еще не исчезнув, успел избавиться от страданий. Я на какой-то момент водворяюсь в ложном представлении о смерти... я мыслю смерть рядом; я мыслю ее, следуя немыслимой логике, я дрейфую за пределы фатальной четы, узы которой связывают смерть и жизнь, противополагая их друг другу» [3, с. 307]. Попытка отдаления от объекта любви не всегда способна спасти тягостное положение вещей и также может привести к тому, что влюбленный «бесчувственно переметнется из разлуки в смерть» [3, с. 317] и даже не станет искать мотив для совершения самоубийства.

Итак, литературно-философский анализ осмысления феномена самоубийства, приведенный в данной работе, неизбежно влечет за собой несколько выводов. Во-первых, литература, которая, по мнению Жоржа Батая, является и «ярко выраженной формой Зла» [2, с. 15], и «вновь обретенным детством» [2, с. 16], нередко погружает читателя в диалектику самоубийства на глубину философии, а философы, обращаясь к изучению проблемы суицида, зачастую переходят в дискурс литературный (к примеру, Жан Поль Сартр в знаменитом романе «Тошнота» (1938)). При этом и литераторы, и философы значительное внимание уделяют добровольному уходу из жизни, совершенному под влиянием любовных переживаний. Хотя главный герой упомянутого романа Ж.П. Сартра, Антуан Рокантен, решает вопрос о самоубийстве в положительном ключе, обретая свободу и надежду на то, что его жизнь кто-нибудь посчитает «драгоценной, почти легендарной» [7, с. 317].

Еще одной чертой, сближающей литературный/литературоведческий и философский дискурсы в вопросе осмысления феномена самоубийства, является то, что в обоих случаях рассмотрению самоубийства не отводится главная роль, данную тему мыслители разного толка чаще затрагивают вскользь. На наш взгляд, в литературе максимальная глубина при погружении в проблему суицида была достигнута в XIX в., главным образом в классических отечественных произведениях, которые сыграли роль в формировании философских воззрений на главные (если придерживаться точки зрения экзистенциалистов) вопросы человеческого бытия.

Если обратиться к вопросу об осмыслении самоубийства с позиций истории философии, мы сможем сделать третий вывод: в философии XX в., как никогда ранее, отмечается особый мрачный пафос в понимании смерти и самоубийства, когда жизнь может рассматриваться как отсрочка фатального исхода, а суицид - как возможность утверждения жизни, чего нельзя было представить в анализе самоубийства еще даже в конце XIX в. И если социолог и социальный философ Эмиль Дюркгейм в трактате «Самоубийство. Социологический этюд» (1897), который был признан эталоном научного труда, основанного на строгом следовании методологии, однозначно говорит, что знает, что такое самоубийство [6, с. 452], проанализировав данный феномен с опорой на статистические материалы, то мыслители разного толка XX в. не делают подобных однозначных заявлений, а все больше задают вопросы, главным из которых по-прежнему остается следующий: «Как возможно самоубийство?»

\section{СПИСОК ЛИТЕРАТУРЫ}

1. Ажимов Ф.Е. Методология «пост-» между философией и литературой (аспекты проблемы) // Культурология. 2010. № 2. С. 72-81.

2. Батай Ж. Литература и зло. М.: Изд-во МГУ, 1994.

3. Барт Р. Фрагменты речи влюбленного. М.: Ad Marginem, 1999.

4. Бланшо М. Пространство литературы. М.: Логос, 2002.

5. Гете И.В. Страдания юного Вертера. М.: ACT, 2021.

6. Дюркгейм Э. Самоубийство. М.: АСТ, 2021.

7. Сартр Ж.П. Тошнота. М.: АСТ, 2021.

8. Чхартишвили Г. Писатель и самоубийство. М.: Захаров, 2019. 


\section{REFERENCES}

1. Azhimov, F.E., 2010. Metodologiya «post-» mezhdu filosofiei i literaturoi (aspekty problemy) ["Post"-methodology between philosophy and literature: aspects of an issue], Kul'turologiya, no. 2, pp. 72-81. (in Russ.)

2. Bataille, G., 1994. Literatura i zlo [Literature and evil]. Moskva: Izdatel'stvo MGU. (in Russ.)

3. Barthes, R., 1999. Fragmenty rechi vlyublennogo [A lover's discourse: fragments]. Moskva: Ad Marginem. (in Russ.)
4. Blanchot, M., 2002. Prostranstvo literatury [The space of literature]. Moskva: Logos. (in Russ.)

5. Goethe, J.W., 2021. Stradaniya yunogo Vertera [The sorrows of young Werther]. Moskva: AST. (in Russ.)

6. Durkheim, E., 2021. Samoubiistvo [Suicide: a study in sociology]. Moskva: AST. (in Russ.)

7. Sartre, J.P., 2021. Toshnota [Nausea]. Moskva: AST. (in Russ.)

8. Chkhartishvili, G., 2019. Pisatel' i samoubiistvo [The writer and suicide]. Moskva: Zakharov. (in Russ.)

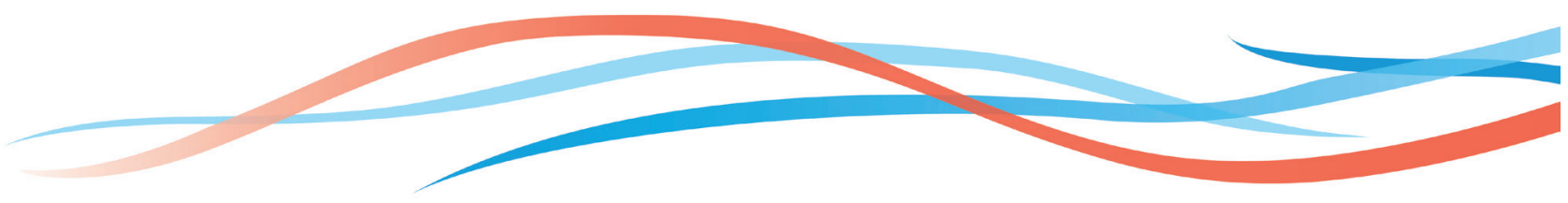

